\title{
Programmed death ligand-1 expression in non-small cell lung cancer in a Western Australian population and correlation with clinicopathologic features
}

\author{
Linda $\mathrm{Ye}^{1,2} \cdot$ Connull Leslie ${ }^{3,4} \cdot$ Angela Jacques $\mathbb{1}^{5,6} \cdot$ Nima Mesbah Ardakani ${ }^{3,4} \cdot$ Benhur Amanuel $^{3,4,7}$. \\ Michael Millward ${ }^{1,2}$
}

Received: 3 September 2018 / Revised: 19 October 2018 / Accepted: 22 October 2018 / Published online: 6 November 2018

(c) United States \& Canadian Academy of Pathology 2018

\begin{abstract}
Immune checkpoint inhibition is an important therapeutic option in patients with non-small cell lung cancer. Programmed cell death ligand-1 (PD-L1) expression may serve as a predictive marker for anti-PD-1/PD-L1 therapies. The relationship between non-small cell lung cancer PD-L1 expression and clinicopathological characteristics remains unclear and there is no population level Australian data. We report the results of PD-L1 testing in patients with non-small cell lung cancer diagnosed at major Western Australian public hospitals served by a single state Pathology provider. We analyzed PD-L1 expression by immunohistochemistry in 241 non-small cell lung cancer specimens using the 22C3 clone on a Dako autostainer platform. Tumor cell PD-L1 expression was scored as Tumor Proportion Score and categorized using pre-specified subsets of $1 \%$, $1-49 \%$ and $\geq 50 \%$ for correlation with clinicopathologic features. PD-L1 Tumor Proportion Score was $1 \%$ in 65 (27\%) cases, $1-49 \%$ in $100(41 \%)$ cases and $\geq 50 \%$ in $76(32 \%)$ cases. PD-L1-positive rate was $92 \%$ in squamous cell carcinomas and $67 \%$ in adenocarcinomas. PD-L1 Tumor Proportion Score was higher in squamous cell carcinomas $(p=0.004)$ and lower in adenocarcinomas $(p=0.003)$. Of the 196 non-squamous carcinomas, 35\% had rat sarcoma viral oncogene homolog $(R A S)$ mutations, $13 \%$ had epidermal growth factor receptor (EGFR) mutations, $2 \%$ had anaplastic lymphoma kinase $(A L K)$ translocations and $2 \%$ had ROS1 translocations. Tumor Proportion Score $\geq 50 \%$ was seen in 34\% (23/68), $28 \%(7 / 25)$ and $25 \%$ (1/4) of RAS, EGFR mutant, and $A L K$ translocated carcinomas, respectively. There was no significant correlation between PD-L1 expression and molecular or genetic abnormalities, or other parameters including age, gender, stage, and smoking status. In our patient cohort, PD-L1 Tumor Proportion Score was significantly higher in squamous cell carcinomas and lower in adenocarcinomas. The overall prevalence of Tumor Proportion Score $\geq 50 \%$ is consistent with that reported in clinical trials.
\end{abstract}

Co-first authors: Connull Leslie, Linda Ye

Linda Ye

lye@linear.org.au

1 Sir Charles Gairdner Hospital, Perth, WA, Australia

2 University of Western Australia, School of Medicine, Crawley, WA, Australia

3 University of Western Australia, School of Pathology and Laboratory Medicine, Crawley, WA, Australia

\section{Introduction}

Recent advances in cancer immunotherapy have dramatically shifted the paradigm of lung cancer treatment. In particular, programmed cell death ligand-1 (PD-L1) and its interaction of the programmed cell death 1 (PD-1) receptor has been shown to play a crucial role in the down regulation of the host

4 Anatomical Pathology, PathWest Laboratory Medicine, QEII Medical Centre, Nedlands, WA, Australia

5 Institute for Health Research, The University of Notre Dame, Fremantle, WA, Australia

6 Department of Research, Sir Charles Gairdner Hospital, Perth, WA, Australia

7 School of Medical and Health Sciences, Edith Cowan University, Perth, WA, Australia 
immune response and is thought to be a key strategy for tumor immune evasion [1-3]. Immune checkpoint inhibitors targeting the PD-1/PD-L1 pathway work by augmenting Tcell-mediated immune responses against cancer cells and have demonstrated significant durable clinical benefit in non-small cell lung cancer patients [4-7]. Some clinical trials have associated PD-L1 expression with higher overall response rates and improved survival outcomes when treated with PD1/PD-L1 axis blockade suggesting that PD-L1 expression may serve as a predictive marker [4-6, 8-10].

Little is known about the intertumoral heterogeneity of PDL1 expression in non-small cell lung cancer. In particular, there have been conflicting results on PD-L1 expression and its association with clinical, pathological, and molecular characteristics. Recent clinical series reported various frequencies of PD-L1 overexpression in non-small cell lung cancer ranging from $7.4 \%$ to $82.1 \%$ [11-28]. Numerous studies including large meta-analyses have attempted to correlate PD-L1 expression with clinicopathologic parameters with conflicting results. Some of the clinical and pathological features that have been linked with higher PD-L1 expression include smoking history, more advanced tumor stage and squamous cell histology [4, 14, 17-19, 26, 29-34]. Some studies have also observed an association between higher PD-L1 expression and epidermal growth factor receptor $(E G F R)$, Kirsten rat sarcoma viral oncogene homolog (KRAS) and anaplastic lymphoma kinase $(A L K)$ oncogenic mutations while others have shown differing results $[4,11,15,21,35-38]$. These discrepancies may be explained by differences in histological types and stages included in the studies, ethnicity of the patient population and heterogeneity in PD-L1 immunohistochemistry methods and cutoff values.

Here, we examined tumor cell PD-L1 expression in nonsmall cell lung cancer patients diagnosed at major Western Australian public hospitals served by a single Pathology provider and the association of PD-L1 expression with clinical features, histology and mutational profile of $E G F R$ and $R A S$ as well as structural rearrangements of $A L K$ and ROSI genes. In cases with next generation sequencing (NGS) data we also examined association between PD-L1 expression and other genetic alterations, including TP53, BRAF, MET, STK11, PIK3CA, APC, CTNNB1, PTEN, MAP2K1, and $S M A D 4$. The information generated from this study will provide better understanding of the pattern of PD-L1 expression in the Australian population.

\section{Materials and methods}

\section{Patients and samples}

This study included 241 patients with histologically confirmed non-small cell lung cancer who had PD-L1 testing on tumor specimens at Pathwest Laboratory Medicine between April 2016 and August 2017. All but one tumor specimen were pre-treatment diagnostic samples. One tumor specimen was obtained from a mediastinal lymph node following disease recurrence after initial treatment with surgery and adjuvant chemotherapy. There were 112 core biopsy or endobronchial specimens, 103 cytology specimens, and 26 tumor resection specimens. Clinical data was retrospectively retrieved from medical records, including age at diagnosis, gender, histologic type, TNM stage (7th AJCC TNM Staging System) and smoking history.

\section{Immunohistochemistry and assessment of PD-L1 expression}

Immunohistochemistry for PD-L1 expression was performed using the PD-L1 22C3 pharmDx immunohistochemical assay on a representative section of tumor after assessment of adequacy. All tissue was fixed in $10 \%$ buffered neutral formalin and routinely processed into paraffin embedded blocks. Cytology specimens were assessed on cell block material, with aspirate concentrated by centrifugation (2000 rpm for $10 \mathrm{~min}$ ). Plasma was added to the cell deposit and this cell suspension mixed with $0.25 \mathrm{~mL}$ of thrombin solution to form a clot, which was then fixed in $10 \%$ buffered neutral formalin and routinely processed into paraffin embedded blocks. Sections were cut at $4 \mu \mathrm{M}$ on Matsunami Platinum Pro charged slides (Matsunami Glass Ind. Ltd, Japan), then dried in an oven at $60^{\circ} \mathrm{C}$ for $60 \mathrm{~min}$. Heat induced epitope retrieval was performed in EnVision $^{\mathrm{TM}}$ Flex Target Retrieval Solution (TRS), at pH 6.1 and $95-99^{\circ} \mathrm{C}$ for $20 \mathrm{~min}$. Slides were incubated for $30 \mathrm{~min}$ in pre-diluted primary $\mathrm{Ab}$ (clone 22C3) and EnVision Flex + detection system, on a DAKO Autostainer Link 48 instrument. Verification of successful reaction on each slide was assessed with tonsil and placenta as external tissue controls.

PD-L1 expression was assessed based on the Tumor Proportion Score [39]. In brief only viable tumor cells are assessed, positivity is defined as any perceptible linear cell membrane staining (partial or complete), the score reflects percentage of positive tumor cells, and any associated immune cells are excluded from scoring.

\section{Molecular and genetic analysis}

Molecular studies were only performed on all nonsquamous cases $(n=196)$. Representative sections of tumor were assessed for adequacy prior to DNA extraction from formalin fixed paraffin blocks. If tumor content was $>$ $50 \%$ five $20 \mathrm{~mm}$ scrolls were placed in an Eppendorf tube, or alternately if the tumor comprised $<50 \%$ of the section, sections were cut and placed onto uncharged glass slides for microdissection. Following dewaxing with three washes of 
xylene and three washes of $100 \%$ ethanol and removal of left over ethanol, the tissue was digested overnight with proteinase $\mathrm{K}$ and DNA was isolated from the digest using the QIAmp DNA FFPE tissue kit (Qiagen, Germany) according to the manufacturer's instructions.

NGS was performed $(n=86)$ on cases with sufficient amount of DNA ( $>150 \mathrm{ng}$ ) using the Illumina miSeq platform with TruSight Tumor 26 Sequencing Panel. Acceptance criteria for mutation calling was greater than $\mathrm{x} 500 \mathrm{read}$ depth and greater an 3\% variant allele frequency, with data analysis pipeline using MiSeq Reporter and Illumina Variant Studio 2.2. The genes tested and exons covered by the TruSight tumor 26 panel are: $A K T$ (exon 2), $A L K$ (exon 23), APC (exon 1-3), BRAF (exon 11, 15), CDHI (exon 8,9,12), CTNNB1 (exon 1,2), EGFR (exon 18,19,20,21), ERBB2 (exon 20), FBXW7 (exon 7,8,9,10,11), FGFR2 (exon 6), AKT (exon 2), FOXL2 (exon 1), GNAQ (exon 4,5,6), GNAS (exon 6,8), KIT (exon 9,11,13,17, 18), KRAS (exon 1,2,3,4), MAP2K1 (exon 2), MET (exon 1,4,13,15,16,17,18,19,20), MSH6 (exon 5), NRAS (exon 1,2,3,4), PDGFRA (exon 11,13,17), PIK3CA (exon 1,2,7,9,20), PTEN (exon 1,2,3,4,5,6,7,8,9), SMAD4 (exon 8, 11), STK11 (exon 1,4,6,8), TP53 (exon $1,2,3,4,5,6,7,8,9,10,11), S R C$ [10].

If DNA content was $<150 \mathrm{ng}(n=110)$, then step-wise mutation testing was initiated. First the Cobas 4800 realtime PCR system for EGFR mutations (covering exons 18, $19,20,21)$ was performed, then if this was negative pyrosequencing [Qiagen Pyromark Q24 instrument with Therascreen KRAS Pyro kit (Cat No 971460)] for KRAS mutations [covering exon 2 (codons 12 and 13) and exon 3 (codon 61)] was performed.

Immunohistochemical stains for ALK1 protein (clone D5F3) and ROS1 protein (clone D4D6) were performed in all non-squamous cases. If only wild-type $E G F R$ and $K R A S$ molecular profile was detected, or if immunohistochemical staining for $A L K 1$ or $R O S 1$ protein was not entirely negative, fluorescence in situ hybridization for $A L K$ breakapart (Vysis probe) and ROS1 breakapart (Vysis probe) was performed $(n=114)$.

\section{Statistical analyses}

PD-L1 expression Tumor Proportion Score was categorized into three groups based on expression values of $<1 \%$, $1-49 \%$, and $\geq 50 \%$. Descriptive statistics for patient demographics and clinical characteristics data were summarized using frequency distributions for categorical data and comparisons between the three PD-L1 expression category groups were made using Pearson's $\chi^{2}$ or Fisher exact tests. Continuous outcome measures were summarized using means, standard deviations and ranges, and oneway ANOVA was used to compare groups. Factors associated with PD-L1 expression categories and tumor types were evaluated using logistic regression analysis with effects summarized using odds ratios and their $95 \%$ confidence intervals. Data was analyzed using IBM SPSS version 24.0 (Armonk, NY). $p$-values $<0.05$ were considered statistically significant.

\section{Results}

Tumor PD-L1 Tumor Proportion Score levels ranged from 0 to $95 \%$. Of the 241 cases, 65 (27\%) did not show any PDL1 staining (Tumor Proportion Score < 1\%), $100(41 \%)$ had partial PD-L1 expression of $1-49 \%$ and $76(32 \%)$ had strong PD-L1 expression of $\geq 50 \%$.

\section{Clinical parameters}

A total of 241 patients with non-small cell lung cancer were included in the study. The median age at diagnosis was 69 years (range 36-95), and 135 patients (56\%) were male. Thirty-two patients (13\%) were never smokers and 200 patients $(83 \%)$ had a smoking history. Of these, 98 were former smokers (having quit smoking $>1$ year prior to diagnosis) and 96 were current smokers (smoking at the time of diagnosis or within 1 year prior to diagnosis). Nine patients $(4 \%)$ had unknown smoking status. Thirty-eight patients $(16 \%)$ had stage I disease at the time of PD-L1 testing, 18 (8\%) were stage II, $46(19 \%)$ were stage III, and $136(56 \%)$ were stage IV according to the 7 th edition of the AJCC TNM staging system. Three patients were unstaged.

The correlation of PD-L1 expression with clinical characteristics is presented in Table 1 . There was no significant correlation between PD-L1 expression and gender, age, tumor stage, or smoking history.

\section{Histologic types}

Histologic types were categorized as adenocarcinoma, squamous cell carcinoma, adenosquamous carcinoma, and non-small cell lung cancer, not otherwise specified (defined by morphology and immunohistochemical profile [40]; the latter defined as non-small cell carcinoma not showing glandular or squamous morphology and lacked expression of TTF 1 or p40/p63; designation of lung origin was based on clinical and radiological findings). One-hundred seventysix cases $(73 \%)$ were adenocarcinomas, $45(19 \%)$ were squamous cell carcinomas, 9 (4\%) were adenosquamous carcinomas, and $11(5 \%)$ were non-small cell lung cancer, not otherwise specified.

In the squamous cell carcinoma cohort, $4(9 \%)$ were PDL1 negative, 27 (60\%) were weakly positive, and 14 (31\%) were strongly positive. Among adenocarcinomas, 58 (33\%) 
Table 1 Correlations between PD-L1 Tumor Proportion Score with clinical features in 241 cases

\begin{tabular}{|c|c|c|c|c|c|c|}
\hline & & $\begin{array}{l}\text { No. of } \\
\text { cases } \\
n=241\end{array}$ & $\begin{array}{l}\text { PD- } \\
\text { L1< } \\
1 \% \\
n=65 \\
(27 \%)\end{array}$ & $\begin{array}{l}\text { PD-L1 } \\
1-49 \% \\
n=100 \\
(41 \%)\end{array}$ & $\begin{array}{l}\text { PD- } \\
\text { L1 } \geq \\
50 \% \\
n=76 \\
(32 \%)\end{array}$ & $p$-value \\
\hline & & $N(\%)$ & & & & \\
\hline \multirow{4}{*}{$\begin{array}{l}\text { Age } \\
\text { (years) }\end{array}$} & $<60$ & $53(22)$ & 15 (28) & $24(45)$ & $14(26)$ & 0.89 \\
\hline & $60-69$ & $75(31)$ & $19(25)$ & $31(41)$ & $25(33)$ & \\
\hline & $70-79$ & $63(26)$ & $20(32)$ & $24(38)$ & $19(30)$ & \\
\hline & $\geq 80$ & $50(21)$ & $11(22)$ & $21(42)$ & $18(36)$ & \\
\hline \multirow[t]{2}{*}{ Sex } & Male & $135(56)$ & 39 (29) & $56(41)$ & $40(30)$ & 0.68 \\
\hline & Female & $106(44)$ & $26(25)$ & $44(41)$ & $36(34)$ & \\
\hline \multirow[t]{2}{*}{$\begin{array}{l}\text { Smoking } \\
\text { status }^{\mathrm{a}}\end{array}$} & $\begin{array}{l}\text { Non- } \\
\text { smoker }\end{array}$ & 32 (14) & $10(31)$ & $14(44)$ & $8(25)$ & 0.68 \\
\hline & Smoker & $200(86)$ & $53(27)$ & $82(41)$ & $65(32)$ & \\
\hline \multirow[t]{4}{*}{ Stage $^{b}$} & I & 38 (16) & $9(24)$ & $20(53)$ & $9(24)$ & 0.43 \\
\hline & II & $19(8)$ & $5(26)$ & $8(42)$ & $6(32)$ & \\
\hline & III & 45 (19) & $9(20)$ & $22(49)$ & $14(31)$ & \\
\hline & IV & $136(57)$ & $43(32)$ & $47(35)$ & $46(34)$ & \\
\hline
\end{tabular}

${ }^{a}$ Nine patients had unknown smoking status

${ }^{\mathrm{b}}$ Three patients were unstaged

were PD-L1 negative, 67 (38\%) were partially positive, and $51(29 \%)$ were strongly positive.

PD-L1 expression significantly differed among histologic types (Table 2). There was higher PD-L1 expression in squamous cell carcinomas compared to other types $(p=$ 0.004), whereas adenocarcinomas had lower PD-L1 expression compared to other types $(p=0.003)$.

Compared to non-squamous cell carcinomas, a significantly higher proportion of squamous cell carcinomas had PD-L1 expression of $1-49 \%(p<0.001)$ and $\geq 50 \%$ $(p=0.025)$. Using univariate logistic regression analysis, the odds of squamous cell carcinomas having partial or strong PD-L1 positivity were significantly higher than having negative PD-L1 expression, with an odds ratio of $5.64(95 \%$ CI $1.87-17.01, p=0002)$ and $3.44(95 \%$ CI $1.07-11.05, p=0.038$ ), respectively.

Conversely, adenocarcinomas were less likely to have PDL1 Tumor Proportion Score of $1-49 \%(p=0.001)$ and $\geq 50 \%$ $(p=0.001)$ than other histological types. Adenocarcinomas were four times less likely to have PD-L1 Tumor Proportion Score $1-49 \%$ (odds ratio $0.25,95 \%$ CI $0.10-0.60, p=0.002$ ) and $\geq 50 \%$ (odds ratio $0.25,95 \%$ CI $0.10-0.62, p=0.003$ ), compared to having negative PD-L1 expression.

We then compared strong (Tumor Proportion Score $\geq$ $50 \%)$ PD-L1-positive tumors with those with partial or negative PD-L1 expression, and did not observe any statistically significant differences in the adenocarcinoma and
Table 2 Correlations between PD-L1 Tumor Proportion Score with histological type

\begin{tabular}{|c|c|c|c|c|c|}
\hline Histology & $\begin{array}{l}\text { No. of } \\
\text { cases } \\
n=241\end{array}$ & $\begin{array}{l}\text { PD- } \\
\mathrm{L} 1< \\
1 \% \\
n=65 \\
(27 \%)\end{array}$ & $\begin{array}{l}\text { PD-L1 } \\
1-49 \% \\
n=100 \\
(41 \%)\end{array}$ & $\begin{array}{l}\text { PD- } \\
\text { L1 } \geq \\
50 \% \\
n=76 \\
(32 \%)\end{array}$ & $p$-value \\
\hline & $N(\%)$ & & & & \\
\hline Adenocarcinoma & $176(73)$ & $58(33)$ & $67(38)$ & $51(29)$ & 0.003 \\
\hline Other & $65(27)$ & $7(11)$ & $33(51)$ & $25(38)$ & \\
\hline Squamous cell & 45 (19) & $4(9)$ & $27(60)$ & $14(31)$ & 0.004 \\
\hline Other & $196(81)$ & $61(31)$ & 73 (37) & $62(32)$ & \\
\hline Adenosquamous & $9(4)$ & $2(22)$ & $3(33)$ & $4(44)$ & 0.70 \\
\hline Other & $232(96)$ & $63(27)$ & $97(42)$ & $72(31)$ & \\
\hline $\mathrm{NSCLC}, \mathrm{NOS}^{\mathrm{a}}$ & $11(5)$ & $1(9)$ & $3(27)$ & $7(64)$ & 0.06 \\
\hline Other & $230(95)$ & $64(28)$ & $97(42)$ & $69(30)$ & \\
\hline
\end{tabular}

${ }^{a}$ NSCLC, NOS: non-small cell lung cancer, not otherwise specified

Statistically significant $\mathrm{p}$ values

squamous cell carcinoma subgroups. However, among the 11 patients with non-small cell lung cancer, not otherwise specified, 7 (64\%) had PD-L1 Tumor Proportion Score $\geq 50 \%$, which was significantly higher compared to other histologic subtypes $(p=0.026)$. The odds of having strong PD-L1 positivity was significantly higher in this group (odds ratio $4.08,95 \%$ confidence interval $1.16-14.40, p=0.02$ ).

\section{Molecular and genomic mutations}

All adenocarcinomas, adenosquamous carcinomas, and nonsmall cell lung cancer, not otherwise specified, were tested for the oncogenic driver mutations of EGFR and $R A S$, and gene rearrangements of $A L K 1$ and ROS1. Of a total of 196 cases, 96 (49\%) had no detectable abnormalities, 68 (35\%) had RAS mutations, 25 (13\%) had EGFR mutations, 4 (2\%) had an $A L K$ translocation, and $3(2 \%)$ had a ROS1 translocation. These four driver abnormalities were mutually exclusive.

Among EGFR mutant tumors, exon 19 deletion (delExon19) was the most common variant and was identified in 14 patients (56\%). Exon 21 variant (Exon21) was identified in 9 patients $(36 \%)$ and 2 patients had other EGFR variants [an Exon 18 codon 719 variant and an exon 20 insertion p.(Val769_Asp770insASV)].

Of the 68 RAS mutant tumors, there were 67 KRAS and 1 $N R A S$ variants. p.Gly12Cys KRAS was the most common variant arising in 24 patients (35\%) followed by p.Gly12Val KRAS variant, seen in 14 patients $(21 \%)$.

The correlation of PD-L1 Tumor Proportion Score with oncogenic driver mutation status in 196 non-squamous carcinoma cases is presented in Tables 3-5. There was no significant correlation between PD-L1 expression and any of the molecular alterations detected. 
Table 3 Correlations between PD-L1 Tumor Proportion Score with oncogenic driver mutation status in 196 non-squamous carcinoma cases

\begin{tabular}{llllll}
\hline & $\begin{array}{l}\text { No. of cases } \\
n=196\end{array}$ & $\begin{array}{l}\text { PD-L1 }<1 \% \\
n=61(31 \%)\end{array}$ & $\begin{array}{l}\text { PD-L1 1-49\% } \\
n=73(37 \%)\end{array}$ & $\begin{array}{l}\text { PD-L1 } \geq 50 \% \\
n=62(32 \%)\end{array}$ & $p$-value \\
\hline EGFR mutation & $25(13)$ & $11(44)$ & $7(28)$ & $7(28)$ & 0.69 \\
RAS mutation & $68(35)$ & $18(26)$ & $27(40)$ & $23(34)$ & $1(25)$ \\
ALK translocation & $4(2)$ & $2(50)$ & $1(25)$ & $2(67)$ \\
ROS1 translocation & $3(2)$ & $0(0)$ & $1(33)$ & $29(30)$ & \\
Pan-wildtype & $96(49)$ & $30(31)$ & $37(39)$ & & \\
\hline
\end{tabular}

Table 4 Correlations between EGFR and RAS mutation genotypes and PD-L1 Tumor Proportion Score

\begin{tabular}{llllll}
\hline & & No. of cases & PD-L1 <50\% & PD-L1 $\geq 50 \%$ & $p$-value \\
\hline EGFR mutation & DelExon19 & $14(56)$ & $11(79)$ & $3(21)$ & 0.43 \\
& Exon21 & $9(36)$ & $6(67)$ & $3(33)$ & \\
& Other & $2(8)$ & & & \\
& p.Gly12Cys mutation & $24(35)$ & $15(62)$ & $9(38)$ & 0.64 \\
& p.Gly12Val KRAS & $14(21)$ & $11(79)$ & $3(21)$ & \\
& p.Gly12Asp KRAS & $10(15)$ & $5(50)$ & $5(50)$ & \\
& p.Gly12Ser KRAS & $7(10)$ & $5(71)$ & $2(29)$ & \\
& p.Glu61His KRAS & $5(7)$ & $3(60)$ & $2(40)$ & \\
& p.Gly12Arg KRAS & $4(6)$ & $3(75)$ & $1(25)$ & \\
& p.Gly12Ala KRAS & $2(3)$ & $2(100)$ & $0(0)$ & \\
& p.Gly13Cys KRAS & $1(2)$ & $0(0)$ & $1(100)$ & \\
& p.Gln61Leu NRAS & $1(1)$ & $1(100)$ & $0(0)$ & \\
\hline
\end{tabular}

In our population of EGFR mutant tumors, strong PD-L1 expression was seen $28 \%$, which is consistent with the prevalence reported in clinical trials. There was strong PDL1 expression in 3/14 (21\%) of 19delExon and 3/9 (33\%) of Exon21 mutant cases, with no significant difference seen between the two genotypes. In tumors harboring $R A S$ variants, there was no significant difference in PD-L1 expression across the different $R A S$ variants cases.

Eighty-six tumors were analyzed for additional gene variants via NGS (Table 5). The most commonly found variant was in the tumor suppressor gene TP53, seen in 40 of the 86 tumor specimens $(47 \%)$. Variants were detected in BRAF, MET, STK11, PIK3CA, APC, CTNNB1, PTEN, $M A P 21 K$, and $S M A D 4$ genes in a small number of patients.

By far the other most common genetic alternation detected via NGS was in the TP53 gene. 30\% (12/40) of TP53-positive tumors had PD-L1 Tumor Proportion Score $\geq 50 \%$ compared to $28 \%$ (13/46) of TP53-negative tumors $(p=0.52)$.

\section{Discussion}

The major significant finding from our study is the differential PD-L1 expression in non-small cell lung cancer
Table 5 Correlations between PD-L1 Tumor Proportion Score and genetic alterations identified by next generation sequencing in 86 cases

\begin{tabular}{|c|c|c|c|c|c|}
\hline & & $\begin{array}{l}\text { No. of cases } \\
n=86\end{array}$ & $\begin{array}{l}\text { PD-L1 }<50 \% \\
n=61(71 \%)\end{array}$ & $\begin{array}{l}\text { PD-L1 } \geq 50 \% \\
n=25(29 \%)\end{array}$ & $p$-value \\
\hline & & $N(\%)$ & & & \\
\hline \multirow[t]{2}{*}{ TP53 } & Positive & $40(47)$ & $28(70)$ & $12(30)$ & 0.52 \\
\hline & Negative & $46(53)$ & $33(72)$ & $13(28)$ & \\
\hline \multicolumn{6}{|c|}{ Other mutations } \\
\hline & $B R A F$ & 4 & $3(75)$ & $1(25)$ & \\
\hline & $M E T$ & 4 & $4(100)$ & $0(0)$ & \\
\hline & PIK3CA & 3 & $1(33)$ & $2(67)$ & \\
\hline & STK11 & 3 & $3(100)$ & $0(0)$ & \\
\hline & $A P C$ & 2 & $1(50)$ & $1(50)$ & \\
\hline & $C T N N B 1$ & 2 & $2(100)$ & $0(0)$ & \\
\hline & PTEN & 2 & $2(100)$ & $0(0)$ & \\
\hline & $M A P 21 K$ & 1 & $1(100)$ & $0(0)$ & \\
\hline & SMAD4 & 1 & $1(100)$ & $0(0)$ & \\
\hline
\end{tabular}

subtypes including adenocarcinoma and squamous cell carcinoma, due to increased proportion of partial (1-49\%) PD-L1 rather than strong $(\geq 50 \%)$ expression. PD-L1 expression was more frequently observed in squamous cell carcinomas and less frequently observed in 
adenocarcinomas. However, when analyzed separately, there was no significant difference between adenocarcinoma and squamous cell carcinoma subtypes in those with Tumor Proportion Score $\geq 50 \%$.

The correlation between PD-L1 expression and squamous histology is concordant with the results of other studies including two recently published meta-analyses [26, 29, 32-34]. These findings suggest that the PD-1/PD-L1 pathway may be utilized more commonly by squamous cell carcinomas to achieve host immune evasion. However, studies have shown that PD-L1 expression in non-small cell lung cancer does not always select patients who are more likely to benefit from checkpoint blockade. For example, PD-L1 expression in squamous cell carcinoma did not impact response rate and patient outcome when treated with nivolumab [7], and first line chemoimmunotherapy combinations significantly improved survival compared to chemotherapy regardless of PD-L1 status [41, 42]. This indicates that PD-L1 alone is not a good predictive biomarker for treatment response and that there are other factors that can affect tumor immunogenicity and response to PD-1/PD-L1 antibodies, such as somatic mutational and neoantigen burden as shown recently by the Checkmate 227 trial [43], as well as other differences in the tumor immune landscape.

Non- $E G F R$ mutated or non- $A L K$ translocated carcinomas with PD-L1 Tumor Proportion Score $\geq 50 \% \quad$ (22C3 pharmDx assay) have been shown to benefit from first line PD-1 inhibitor therapy with pembrolizumab when compared with platinum doublet chemotherapy, with a higher overall response rate of $44.8 \%$ and greater progression free survival of 10.3 months [44]. In our patient cohort, we did not observe any significant predictors of strong PD-L1 expression except for the non-small cell lung cancer, not otherwise specified histologic type. It is not possible to ascertain the significance of this given the small sample in our cohort.

The association between PD-L1 expression and molecular profiles in non-squamous carcinomas has been studied extensively and remains controversial. Several reports suggest that EGFR mutations were associated with higher PD-L1 expression [11, 15, 21, 35, 36]. Conversely other studies show that PD-L1 positivity was more frequent in EGFR wild-type tumors [45-47]. Recent reports have also shown a significant association between PD-L1 expression and KRAS mutations [4, 37] and $A L K$ translocations [38], while other studies have failed to find such relationships [11, 14, 20, 27, 29, 37, 48, 49]. Our study did not show any significant correlation between PD-L1 expression and underlying molecular aberrations.

Our cases mostly consisted of adenocarcinomas and TP53 was the most commonly detected genetic abnormality identified via NGS. Although three groups have demonstrated that TP53 mutated adenocarcinomas expressed higher levels of PD-L1, especially in the presence of a coexisting KRAS mutation [50-52], we did not see a significant difference when using the PD-L1 Tumor Proportion Score cutoff of $50 \%$. Our cohort only had eight patients with synchronous TP53 and KRAS mutations, limiting the statistical power of the analysis.

Finally, some studies have shown that PD-L1 expression correlates with smoking history $[4,17,29-31]$; however, other studies have failed to demonstrate such associations [20-22, 45, 48, 53]. PD-L1 expression has also been linked with more advanced tumor stage $[14,18,19,26]$. In our patient cohort, we did not find a significant link between PD-L1 expression and any of the clinical variables.

There are a few limitations to our study. This study included patients treated at a single center, which can limit the generalizability of the results. Some of the tumor subsets such as those with $A L K 1$ and ROS1 alterations had a small number of patients which limits the statistical analysis power in these groups. A common drawback shared with other studies is the lack of standardized tumor PD-L1 expression cutoff values. To increase the clinical translational relevance of this study, we chose three PDL1 expression cutoffs that are used in clinical trials and are relevant to the current method of selecting patients for anti-PD-1/PD-L1 therapy. Furthermore, due to intratumoral and intra-patient tumor heterogeneity, especially in patients with metastatic disease who underwent tumor sampling of only a single site, the PD-L1 expressions observed might not be representative of the patient's disease. Lastly, the dataset was collected retrospectively and subject to bias as a result.

Our study showed significant differences in PD-L1 expression between lung squamous cell carcinomas and adenocarcinomas, supporting the notion of biological and immunological diversity among non-small cell lung cancer subtypes. How this influences tumor response to immune checkpoint blockade is still unclear and further research is needed to advance our understanding of the complexities of the tumor microenvironment and tumor immunology.

\section{Compliance with ethical standards}

Conflict of interest Michael Millward-Advisory Board for Merck Sharpe \& Dohme; Benhur Amanuel-Advisory Board for Merck Sharpe \& Dohme. The other authors declare that they have no conflict of interest.

\section{References}

1. Keir ME, Butte M, Freeman GJ, Sharpe AH. PD-1 and its ligands in tolerance and immunity. Annu Rev Immunol. 2008; 26:677-704. 
2. Nishimura H, Honjo T. PD-1: an inhibitory immunoreceptor involved in peripheral tolerance. Trends Immunol. 2011;22:265-8

3. Watanabe N, Gavrieli M, Sedy JR, Yang J, Fallarino F, Loftin SK et al. BTLA is a lymphocyte inhibitory receptor with similarities to CTLA-4 and PD-1. Nat Immunol. 2003;4:670-9.

4. Garon EB, Rizvi NA, Hui R, Leighl N, Balmanoukian AS, Eder J et al. Pembrolizumab for the treatment of non-small-cell lung cancer. N Engl J Med. 2015;372:2018-28.

5. Topalian SL, Hodi FS, Brahmer JR, Gettinger SN, Smith DC, McDermott DF et al. Safety, activity, and immune correlates of anti-PD-1 antibody in cancer. N Engl J Med. 2012;366:2443-54.

6. Borghaei H, Paz-Ares L, Horn L, Spigel DR, Steins M, Ready NE et al. Nivolumab versus docetaxel in advanced nonsquamous nonsmall-cell lung cancer. N Engl J Med. 2015;373:1627-39.

7. Brahmer J, Reckamp KL, Baas P, Crinò L, Eberhardt WE, Poddubskaya $\mathrm{E}$ et al. Nivolumab versus docetaxel in advanced squamous-cell non-small-cell lung cancer. $\mathrm{N}$ Engl $\mathrm{J}$ Med. 2015;373:123-35.

8. Herbst RS, Soria JC, Kowanetz M, Fine GD, Hamid O, Gordon MS et al. Predictive correlates of response to the anti-PD-L1 antibody MPDL3280A in cancer patients. Nature. 2014; 515:563-7.

9. Herbst RS, Baas P, Kim DW, Felip E, Pérez-Gracia JL, Han JY et al. Pembrolizumab versus docetaxel for previously treated, PDL1-positive, advanced non-small-cell lung cancer (KEYNOTE010): a randomised controlled trial. Lancet. 2016;387: 1540-50.

10. Fehrenbacher L, Spira A, Ballinger M, Kowanetz M, Vansteenkiste $\mathbf{J}$, Mazieres $\mathbf{J}$ et al. Atezolizumab versus docetaxel for patients with previously treated non-small-cell lung cancer (POPLAR): a multicenter, open-label, phase 2 randomised controlled trial. Lancet. 2016;387:1837-46.

11. Tang Y, Fang W, Zhang Y, Hong S, Kang S, Yan Y et al. The association between PD-L1 and EGFR status and the prognostic value of PD-L1 in advanced non-small cell lung cancer patients treated with EGFR-TKIs. Oncotarget. 2015;6:14209-19.

12. Koh J, Go H, Keam B, JKim MY, Nam SJ, Kim TM et al. Clinicopathologic analysis of programmed cell death-1 and programmed cell death-ligand 1 and 2 expression in pulmonary adenocarcinoma: comparison with histology and driver oncogenic alteration status. Mod Pathol. 2015;28:1154-66.

13. Lin C, Chen X, Li M, Liu J, Qi X, Yang W et al. Programmed Death-Ligand 1 expression predicts tyrosine kinase inhibitor response and better prognosis in a cohort of patients with epidermal growth factor receptor mutation-positive lung adenocarcinoma. Clin Lung Cancer. 2015;16:e25-35.

14. Zhang Y, Wang L, Li Y, Pan Y, Wang R, Hu H et al. Protein expression of programmed death 1 ligand 1 and ligand 2 independently predict poor prognosis in surgically resected lung adenocarcinoma. Oncotarget. 2014;7:567-73.

15. Azuma K, Ota K, Kawahara A, Hattori S, Iwama E, Harada T et al. Association of PD-L1 overexpression with activating EGFR mutations in surgically resectable non-small cell lung cancer. Ann Oncol. 2015;25:1935-40.

16. Boland JM, Kwon ED, Harrington SM, Wampfler JA, Tang H, Yang $\mathrm{P}$ et al. Tumor B7-H1 and B7-H3 expression in squamous cell carcinoma of the lung. Clin Lung Cancer. 2013;14:157-63.

17. Calles A, Liao X, Sholl LM, Rodig SJ, Freeman GJ, Butaney M et al. Expression of PD-1 and its ligands, PD-L1 and PD-L2, in smokers and never smokers with KRAS mutant lung cancer. J Thorac Oncol. 2015;10:1726-35.

18. Chen YB, Mu CY, Huang JA. Clinical significance of programmed death-1 ligand-1 expression in patients with non-small cell lung cancer: a 5-year-follow-up study. Tumori. 2012; 98:751-5.
19. Chen YY, Wang LB, Zhu HL, Li XY, Zhu YP, Yin YL et al. Relationship between programmed death-ligand 1 and clinicopathological characteristics in non-small cell lung cancer patients. Chin Med Sci J. 2013;28:147-51.

20. Cooper WA, Tran T, Vilain RE, Madore J, Selinger CI, KohonenCorish $\mathrm{M}$ et al. PD-L1 expression is a favorable prognostic factor in early stage non-small cell carcinoma. Lung Cancer. 2015;89:181-8.

21. D'incecco A, Andreozzi M, Ludovini V, Rossi E, Capodanno A, Landi $\mathrm{L}$ et al. PD-1 and PD-L1 expression in molecularly selected non-small-cell lung cancer patients. $\mathrm{Br} \mathrm{J}$ Cancer. 2015;112:95-102.

22. Kim MY, Koh J, Kim S, Go H, Jeon YK, Chung DH. Clinicopathological analysis of PD-L1 and PD-L2 expression in pulmonary squamous cell carcinoma: Comparison with tumorinfiltrating $\mathrm{T}$ cells and the status of oncogenic drivers. Lung Cancer. 2015;88:24-33.

23. Konishi J, Yamazaki K, Azuma M, Kinoshita I, Dosaka-Akita H, Nishimura M. B7-H1 expression on non-small cell lung cancer cells and its relationship with tumor-infiltrating lymphocytes and their PD-1 expression. Clin Cancer Res. 2004;10:5094-100.

24. Mao YX, Li W, Chen K, Xie Y, Liu Q, Yao M et al. B7-H1 and B7-H3 are independent predictors of poor prognosis in patients with non-small cell lung cancer. Oncotarget. 2015;6:3452-61.

25. Mu CY, Huang JA, Chen Y, Chen C, Zhang XG. High expression of PD-L1 in lung cancer may contribute to poor prognosis and tumor cells immune escape through suppressing tumor infiltrating dendritic cells maturation. Med Oncol. 2011;28:682-8.

26. Velcheti V, Schalper KA, Carvajal DE, Anagnostou VK, Syrigos $\mathrm{KN}$, Sznol M et al. Programmed death ligand-1 expression in nonsmall cell lung cancer. Lab Invest. 2014;94:107-16.

27. Yang CY, Lin MW, Chang YL, Wu CT, Yang PC. Programmed cell death-ligand 1 expression in surgically resected stage I pulmonary adenocarcinoma and its correlation with driver mutations and clinical outcomes. Eur J Cancer. 2014;50:1361-9.

28. Ilie M, Falk AT, Butori C, Chamorey E, Bonnetaud C, Long E et al. PD-L1 expression in basaloid squamous cell lung carcinoma: Relationship to PD-1+and CD8+tumor infiltrating T cells and outcome. Mod Pathol. 2016;29:1552-64.

29. Igawa S, Sato Y, Ryuge S, Ichinoe M, Katono K, Hiyoshi Y et al. Impact of PD-L1 expression in patients with surgically resected non-small-cell lung cancer. Oncology. 2017;92:283-90.

30. Takada K, Okamoto T, Shoji F, Shimokawa M, Akamine T, Takamori $\mathrm{S}$ et al. Clinical significance of PD-L1 protein expression in surgically resected primary lung adenocarcinoma. J Thorac Oncol. 2016;11:1879-90.

31. Xia H, Shen J, Hu F, Chen S, Huang H, Xu Y et al. PD-L1 overexpression is associated with a poor prognosis in Asian non-small cell lung cancer patients. Clin Chim Acta. 2017;469:191-4.

32. Li J, Chen Y, Shi X, Le X, Feng F, Chen J et al. A systematic and genome-wide correlation meta-analysis of PD-L1 expression and targetable NSCLC driver genes. J Thorac Dis. 2017;9:2560-71.

33. Zhang M, Li G, Wang Y, Wang Y, Zhao S, Haihong P et al. PDL1 expression in lung cancer and its correlation with driver mutations: a meta-analysis. Sci Rep. 2017;7:10255.

34. Shimoji M, Shimizu S, Sato K, Suda K, Kobayashi Y, Tomizawa K et al. Clinical and pathologic features of lung cancer expression programmed cell death ligand 1 (PD-L1). Lung Cancer. 2016;98:69-75.

35. Akbay EA, Koyama S, Carretero J, Altabef A, Tchaicha JH, Christensen CL et al. Activation of the PD-1 pathway contributes to immune escape in EGFR-driven lung tumors. Cancer Discov. 2013;3:1355-63.

36. Chen N, Fang W, Zhan J, Hong S, Tang Y, Kang S et al. Upregulation of PD-L1 by EGFR activation mediates the immune escape in EGFR-driver NSCLC: implication for optional immune 
targeted therapy for NSCLC patients with EGFR mutation. J Thorac Oncol. 2015;10:910-23.

37. Huynh T, Oyarvide VM, Uruga H, Bozkurtlar E, Gainor JF, Hata $\mathrm{AN}$ et al. Clinicopathologic and molecular parameters of lung adenocarcinoma (ADC) associated with programmed cell death ligand 1 (PD-L1) protein expression. J Clin Oncol. 2015;33:abstr 7555.

38. Ota K, Azuma K, Kawahara A, Hattori S, Iwama E, Tanizaki J et al. Induction of PD-L1 expression by the EML4-ALK oncoprotein and downstream signaling pathways in non-small cell lung cancer. Clin Cancer Res. 2015;21:4014-21.

39. Roach C, Zhang N, Corigliano E, Jansson M, Toland G, Ponto G et al. Development of a companion diagnostic PD-L1 immunohistochemistry assay for pembrolizumab therapy in non-small-cell lung cancer. Appl Immunohistochem Mol Morphol. 2016; 24:392-7.

40. Travis WD, Brambilla E, Nicholson AG, Yatabe Y, Austin JHM, Beasley MB et al. The 2015 World Health Organization classification of lung tumors. Impact of genetic, clinical and radiologic advances since the 2004 classification. J Thorac Oncol. 2015;10:1243-60.

41. Paz-Ares LG, Luft A, Tafreshi A, Gumus M, Mazieres J, Hermes B et al. Phase 3 study of carboplatin-paclitaxel/nab-paclitaxel with or without pembrolizumab for patients with metastatic squamous non-small cell lung cancer. J Clin Oncol 2018;36:abstr 105.

42. Jotte RM, Cappuzzo F, Vynnychenko I, Stroyakovskiy D, Rodriguez-Abreu D, Hussein M et al. Impower131: Primary PFS and safety analysis of a randomized phase III study of atezolizumab + carboplatin + paclitaxel or nab-paclitaxel vs carboplatin +nab-paclitaxel as 1L therapy in advanced squamous NSCLC. J Clin Oncol 2018;36:abstr LBA9000.

43. Hellmann MD, Ciuleanu TE, Pluzanski A, Lee JS, Otterson GA, Audigier-Valette $\mathrm{C}$ et al. Nivolumab plus ipilimumab in lung cancer with high tumor mutational burden. $\mathrm{N}$ Engl $\mathrm{J}$ Med. 2018;378:2093-104.

44. Reck M, Rodriguez-Abreu D, Robinson AG, Hui R, Csőszi T, Fülöp A et al. Pembrolizumab versus chemotherapy for PD-L1- positive non-small-cell lung cancer. $\mathrm{N}$ Engl $\mathrm{J}$ Med. 2016;375:1823-33.

45. Song Z, Yu X, Cheng G, Zhang Y. Programmed death-ligand 1 expression associated with molecular characteristics in surgically resected lung adenocarcinoma. J Transl Med. 2016;14:188.

46. Inoue Y, Yoshimura K, Mori K, Kurabe N, Kahyo T, Mori H et al. Clinical significance of PD-L1 and PD-L2 copy number gains in non-small-cell lung cancer. Oncotarget. 2016;7:32113-28.

47. Cha YJ, Kim HR, Lee CY, Cho BC, Shim HS. Clinicopathological and prognostic significance of programmed cell death ligand-1 expression in lung adenocarcinoma and its relationship with p53 status. Lung Cancer. 2016;97:73-80.

48. Rangachari D, VanderLaan PA, Shea M, Le X, Huberman MS, Kobayashi SS et al. Correlation between classic driver oncogene mutations in EGFR, ALK, or ROS1 and 22C3-PD-L1 $\geq 50 \%$ expression in lung adenocarcinoma. J Thorac Oncol. 2017;12:878-83.

49. Schmidt LH, Kümmel A, Görlich D, Mohr M, Bröckling S, Mikesch JH et al. PD-1 and PD-L1 expression in NSCLC indicate a favorable prognosis in defined subgroups. PLoS ONE. 2015;10: e0136023.

50. Skoulidis F, Byers LA, Diao L, Papadimitrakopoulou VA, Tong $\mathrm{P}$, Izzo $\mathrm{J}$ et al. Co-occuring genomic alterations define major subsets of KRAS-mutant lung adenocarcinoma with distinct biology, immune profiles, and therapeutic vulnerabilities. Cancer Discov. 2015;5:860-77.

51. Dong ZY, Zhong WZ, Zhang XC, Su J, Xie Z, Liu SY et al. Potential predictive value of TP53 and KRAS mutation status for response to PD-1 blockade immunotherapy in lung adenocarcinoma. Clin Cancer Res. 2017;23:3012-24.

52. Scheel AH, Ansén S, Schultheis AM, Scheffler M, Fischer RN, Michels S et al. PD-L1 expression in non-small cell lung cancer: Correlations with genetic alteration. Oncoimmunology. 2016;5: e1131379.

53. Sorensen SF, Zhou W, Dolled-Filhart M, Georgsen JB, Wang Z, Emancipator $\mathrm{K}$ et al. PD-L1 expression and survival among patients with advanced non-small cell lung cancer treated with chemotherapy. Transl Oncol. 2016;9:64-9. 